\title{
Campus environment a catalyst to student misconduct in Malawian universities
}

Kayange, Jimmy Jaston $\bowtie$

The Catholic University of Malawi, Malawi (jastonjimmy@yahoo.com)

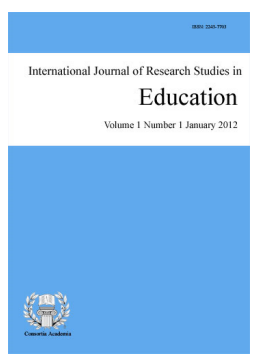

Accepted: 7 December 2020

ISSN: 2243-7703 Online ISSN: 2243-7711

OPEN ACCESS

\section{Abstract}

Even though learning institutions are considered places where good values and manners are learned, institutions of higher learning in Malawi seems to be breeding ground for misbehavior, contradicting the very purpose of these institutions. This study sought to explore the factors contributing to student misbehavior in Malawian Universities. The study used one of the public universities in Malawi as a case study. Findings indicate that institutional culture and poor management style are some of the factors that contribute to student misbehavior in these institutions. The study also discovered that enforcement of rules and regulations, and counseling are some of the ways of addressing student misbehavior. Further, the study argues that student misconduct erodes the credibility of the institution and compromises the holistic development of students. The study recommends the inculcation of a sense of ownership in students so that they know the importance of their institution and how it will define their future. The study also recommends that there is a need to conduct awareness training and in-service training among staff members so that they know their professional conduct as well as how to manage issues regarding misconduct.

Keywords: development; environment; harassment; institutional culture; misbehavior 


\section{Campus environment a catalyst to student misconduct in Malawian universities}

\section{Introduction}

The university environment is considered an educationally purposeful community where faculty and students share academic goals and work together to strengthen teaching and learning (Boyer, 1990; Rubio, 2014). While studying at a university, students develop their identity and other core values for the betterment of their own future experiences (Long, 2012). During this period, learners not only gain knowledge but also learn about themselves, how to behave, as well as how to interact with others (South African Council for Educators, 2011). This suggests universities serve as one of the important socializing mechanisms. Thus, universities must facilitate the holistic development of students (Evans et al., 2010; Iorga et al., 2013; Long, 2012) by creating an environment conducive to the development of core values of good behavior.

Nonetheless, in most universities, issues of student misbehaviors are prevalent. In particular, student misbehavior in most Malawian universities is widespread. For example, in the 2015 academic year, a student leader at one of the universities in Malawi defrauded the institution of approximately $\$ 10,000$ by creating ghost students who were receiving government-funded upkeep allowance (Singini, 2015). In the same year, another public university expelled eight students for cheating during an exam (Mkandawire, 2015). In 1994, a study done at one of the public universities in Malawi found that $12.6 \%$ of female students had been raped at a university campus (Phiri et al., 1994). The same study also revealed that $67 \%$ of female students had been sexually harassed mainly by their fellow students.

The prevalence of student misbehavior in the universities in Malawi contradict Fuchs's (2008) and Long's (2012) arguments that learning institutions are shelters of good manners, human values, and help develop core values for the good of students' own adulthood experiences. The purpose of the study was therefore to explore factors contributing to student misbehavior in Malawian universities. To achieve this purpose, these questions were explored:

$>$ What are the factors contributing to student misbehavior in Malawian universities?

$>$ How can student misbehavior be addressed?

$>$ What is the impact of student misbehavior on student development?

\subsection{The concept of student misbehavior}

Student misbehaviors are behaviors that hinder the teaching-learning process or affect it negatively (Basar 2009). Korkmaz (2013) listed the characteristic of student misbehaviors as; hindering learning, risking safety, giving damage to properties, and blocking socialization. Yigit (2018) groups student misbehavior as; a) individual behaviors such as being unprepared for the lessons, not paying attention to the lesson, talking without permission, lying; b)behaviors towards pears such as holding a grudge of their success, complaining, giving nicknames, bullyragging; c) behavior towards the teacher such as not fulfilling a duty, opposing and sitting inconveniently. Student misbehavior may further include; protest or demonstration that block streets right of way or sidewalks, jeopardize the safety of individuals or the integrity of the college or other property; intimidation, harassment, or threats. Literature indicates various terms to describe problematic behavior such as misbehavior, indiscipline, and misconduct (Finn et al., 2008)

\subsection{The environment and student behavior}

Research indicates various reasons for student's misbehavior. Some of the misbehavior is said to stem from the classroom while others stem outside the classroom (Erdem \&Kocyigit, 2019). These scholars further state 
that misbehavior is associated with family-related issues, physical properties of classrooms, curriculum-related problems, or teachers classroom management abilities.

Environments have a powerful influence on behavior (Kuh, 2000). Students and their environment influence each other in a transactional relationship (Evans et al., 2010). Walsh (cited in Evans et al., 2010, p. 168) argues that people behave in highly similar ways in specific environments regardless of their difference. He further states that individuals will enter subcultures that match their values and characteristics. Similarly, Bruner (as cited in Wearmouth et al., 2005) suggests that the cultural context in which a child is reared shapes his or her thinking and provides tools, a "cultural toolkit" for organizing meaning in ways that can be communicated to others (p. 54). Kuh et al. (2006) further support that student perceptions of the environment, and its norms and values influence how they think (and probably how they behave)

\subsection{College environment and student development}

Rodgers (1990) argues that student development concerns the holistic development a student. It involves the application of human development concepts in a post-secondary setting so that everyone involved can master the increasingly complex developmental task and achieve self-direction and become interdependent (Miller \& Prince cited in Evans et al., 2010). Drum (cited in Hurst, 1987) suggests that development occurs in seven dimensions.

The dimensions include; a) cognitive development, b) social development, c) moral/ethical developmental, d) Physical development, e) aesthetic development, f) interpersonal development, and g) identity formation. He suggests that both curricular and co-curricular activities provide opportunities for development in different dimensions. This entails that the university environment in its totality plays a crucial role in character development. On a much-complicated note as regards student development and college environment Erickson, noted that student behavior emanates within the internal dynamics, and the influences are mainly related to identity development. Erikson stressed that identity connotes both "a persistent sameness within oneself and a persistence sharing of some kind of essential character with others" (Evans et al., 2010 p. 51).

In agreement with Erickson, Pezza, and Bellotti (1995) further state that many college students are within the age of 18-22, the age group that negotiates life tasks related to cognitive development and identity integration. Students are tasked to form their identity at a time they are not under direct parental supervision (Barbot \& Hunter, 2012). This also agrees with Tinto's 1993 interactionalist theory which postulates that students are in a transition period during which they interact in new ways with new members of the new group to seek membership (Tinto, 1993). Dannels (1997) further states that students are also having their first experience with independence. Long (2012) also suggested that good behavior is that which pleases others and probably some students behave to please others. All these suggest that the campus environment has several implications for student holistic development.

\section{Methods}

The study was done at a public university in Malawi. This university is one of the biggest and prestigious public universities in the country. It approximately enrolls 10,000 students. Due to limited spaces available, selection to the university is very competitive. Only a handful of successful candidates get selected for the university making it very prestigious. The university faces a lot of challenges. For example, the university does not have sufficient resources to sustain enrollment growth and improve quality education. Consequently, the university often utilizes overcrowded classrooms, poor teaching aids, and inadequately stocked libraries.

The study used a qualitative case study research design with a public university as a case study. This university was sampled purposively and conveniently because it is one of the biggest and prestigious universities in Malawi. Data was largely purposively collected from management, faculty members and students doing their studies at the university. 
Purposive sampling is used to access people who have in-depth knowledge about particular issues by their professional role, power, and access to networks, expertise, or experience (Cohen et al., 2007). The researcher also used snow bolling to identify students that had a history of misconduct. The researcher used the student union leaders to refer him to those students that have a history of misbehavior to understand the reasons behind their misbehavior, and how this has affected them.

The researcher used structured interviews for all categories of participants. Participants were asked questions related to factors influencing student misbehavior, ways of addressing student misbehavior, and the impact of student misbehavior on student development. Interviews provide researchers with information from a variety of perspectives, and can also help to identify other sources of evidence (Hays, 2004).

The observation was used to augment data collected from interviews. The environment was intensely observed to understand any element that might contribute to student misbehavior. Documents such as student handbooks were analyzed to see any diversions or similarities with the observations and interviews. The most important use of documents in a case study is to augment evidence from other sources (Yin, 2009). The use of different methods of collecting data was necessary for triangulation.

The researcher organized the collected data and produced transcripts. After the transcription process, the researcher read the data again to obtain a general sense of the information and to reflect on its overall meaning as Creswell (2003) recommends. Finally, the researcher analyzed the data through personal interpretation and in reference to literature and theories. Hays (2004) recommends that anticipated information that arises from the data collection or analysis should be discussed in line with the literature review. The researcher used pseudonyms for participants such as student 1 or management 1 to keep confidentiality of participants.

\section{Results and discussions}

This study aimed at exploring factors influencing student's misbehavior. This part presents the findings in line with this purpose.

\subsection{Factors influencing student's misbehavior}

Findings indicate several factors influencing student's misbehavior. The first factor is the institutional culture. The study has found that certain ways of behavior are embedded in the institutional culture, and it is viewed as acceptable and normal. Such behavior is tolerated and continues to exist. Examples of such behavior include; yelling, alcohol, and harassment, insults, and abusive words. The study discovered that management and students alike do not see these behaviors as strange because it happens daily. As such, the study discovered that offenders from such behavior are rarely reprimanded because it is believed by the university that it is normal for students to behave in such a manner. For example, these participants stated;

...the social norms of the institution, what students inherit from their formal students, what they (student) think a college person is supposed to do is what is making students misbehave ....(student 1personal interview, August 8 2020)

....when insulting or shouting at someone, it's like normal, you don't care. You can talk whatever way you want whether it hurts someone or not, you can't care. So students tend to do anything they want, it's normal.... (Student 4 personal interview, August 8 2020)

...because the one you are shouting at doesn't know you and you don't know him either, you are just doing that out of excitement. You don't have any intention of harassing anybody, it's a tradition. It's something that shows you are happy with college life... (Student 7 personal interview, August 8 2020)

...in fact, those are just minor issues because even the people who are called names are used to it 
and they are always happy to say oh! University students are passing by. It isn't a kind of harassment, no, it is not. It's just excitement.... ( Student 3 personal interview, August 8 2020)

Findings suggest that students do not view the misconduct as misconduct per se but rather excitement and those who are offended do not interpret it as such since it is traditional at the university. This suggests that it is the environment that tolerates such kind of behavior to the extent that stakeholders see it as normal. The environment that accepts this behavior enables other new students that get enrolled to get socialized and cultured to this kind of behavior and behave likewise. This agrees with Kuh (2000) who argues that behavior development is a product of thousands of encounters over an extended period with peers and faculty who model desired attitudes and values. More so, the findings echo Bruner (as cited in Wearmouth et al. 2005) argument that the cultural context in which students are reared provides a cultural toolkit for behavior. Kuh et.al (2006) further states that student perceptions of the environment, and its norms and values influence how they think and probably how they behave. It is no doubt that the cultural contexts within which the students are living influence their behavior.

The other factor is peer influence/group thinking. The study discovered that peer influence and group thinking influence student behavior. It was found that when students are in a group they feel secure because they know whatever happens when an offense is committed, will be dealt with as a group, not as an individual. For example this participant stated:

....when you are in a group, it is like there is no individual responsibility for whatever happens. It's like the responsibility is more of a group, you feel nobody is seeing you; you feel you can't be traced ... you can't take it as a personal responsibility to the people whom you are insulting or harassing... (student 8 personal interview, August 8 2020)

Similarly, findings suggest that in social groups, some students want to impress their fellow members. For instance, one participant gave an example of a student who causes a lot of trouble at the campus but well behaved and an exemplary person at home. This confirms Long's (2012) argument that in moral development good behavior is that which pleases others. In this case, students are developing their identity and copy whatever is acceptable in that society so that they identify with others. In line with this, Tinto's interactionalist theory postulates that students are in a transition period during which they interact in new ways with new members of the new group to seek membership (Tinto, 1993). Similarly, Walsh (cited in Evans et al., 2010) suggests that, regardless of differences, students behave similarly in similar environments. If the environment is misconduct free, students would join groups that are exemplary and copy from each other the good behavior.

Another factor is Management Style. The study discovered that management cannot handle students and this contributes to their misbehavior. For example, participant stated:

...management has problems; sometimes they deliberately put a blind eye on the misconduct. So what I am trying to say is that even though we broke the window, the college never asked us to pay anything..... we did not pay anything, yet they knew what happened.... The whole institutional stakeholder saw what happened...' (Student 6personal interview, August 8 2020)

Some students also noted that sometimes they commit offenses not because they would like to but because they have failed to reach consensus with management on certain minor issues. Participants mentioned instances where university introduces some policies that affect students without considering students or informing them before introducing such policies. Participants mentioned that instances like these infuriate students who then participate in unnecessary demonstrations and riots at the institution. More importantly, participants mentioned delays in payment of student allowances which causes students to stage demonstrations and riots. As students riot, they commit other offenses such as blocking the roads, looting people's goods, breaking institutional properties, yelling at passersby, among others. 
This finding support Teferra and Altbach's (2004) argument that African universities suffer from poor, inefficient, and highly bureaucratic management systems and poorly trained and poorly qualified personnel. As such, they fail or take too long to respond to students' queries. Nonetheless, no participant mentioned poor training or qualification of management. However, the findings support Nkinyangi (1991) who suggested that among others, student indiscipline is worsened by delay in paying student allowances.

Another factor is poor enforcement of codes of conduct. Findings indicate that despite the provision of the student handbook where codes of conduct are stipulated, students still misbehave. Resultantly, most participants feel that these rules and regulations are not efficiently enforced. For example, student 5 argued, "there are no tangible rules that prevail at the university that would deter students from engaging in bad acts. There is also a lack of punitive measures for those found guilty hence students continue to misbehave." (Personal interview, August 8 2020) This supports Payne's (as cited in Mayhew et al., 2011) argument that campuses often lack a set of protocols for responding to misconduct. However, one may argue that because of the institutional culture stakeholders do not recognize the misbehavior hence to some extent rendering the code of conduct ineffectual.

Findings further indicate a lack of student activities as a contributing factor towards student's misconduct. Studies suggest that significant participation in campus activities and satisfaction with college experiences increase student persistence (Astin, 1984; Long, 2012), and possibly continued good behavior. However, participants in this study disclosed that few social and academic activities are organized for them. As such, this makes them feel dejected, and loiter around, have time for alcohol consumption, and do other unnecessary activities. On the contrary, some participants argued that students do not like to participate in activities organized by the institution, possibly due to the unappealing nature of the activities. Nonetheless, studies show that students feeling of dejection leads to a sense of not mattering (Hamrick et al., 2002) which increases the likelihood of engaging in misbehavior.

Similarly, Astin (1984) suggests that the amount of student learning and development is directly proportional to the amount of involvement in educational programs. This entails that as a student are involved in institutional activities, they develop a sense of belonging and connection to the institution. This, in turn, reduces the likelihood of engaging in misconduct. This, however, must be noted with prudence since some studies indicate student involvement may increase the likelihood of engaging in criminal activities (Wynne \& Joo, 2011). For instance, in the case of this study, due to increased cases of student misbehavior at the institution, student involvement in institutional activities may expose them to such misbehavior.

\subsection{Factors influencing student's misbehavior}

The study discovered several ways that the institution could use to address the misbehavior. One of the ways is the enforcement of rules and regulations. The study discovered that upon enrollment, students and staff members at the institution are given rules and regulations to guide their behavior. Most of these rules are contained in student and staff members' handbook and residence agreement forms. More importantly, on the first page of the rules and regulations handbook, it is written that 'ignorance of the rules and regulations contained in this document is no excuse'. The purpose of the rules and regulations is to ensure that there is an order for the smooth running of the institution. The end goal is to ensure the successful completion of studies by students. In the student handbook, it is stated that:

The framework of rules and regulations can only assist in completing the educational process and molding the students into good citizens. Students are expected to adhere to these rules and regulations and as a general principle to conduct themselves at all times whether in college or away from it in a manner that would promote the good name of students themselves and above all the good reputation of the university (p. 3)

In line with this, Burke et.al (2014) suggested that rules and regulations establish a psychological contract between students and institutions. It is therefore expected that students would abide by these rules and 
regulations. However, as already indicated somewhere in this document, the institutional culture which accepts the misbehavior renders the rules and regulations ineffective.

The study also discovered that counseling is one of the ways of addressing student misbehavior. It is common knowledge that students are young people who are affected by several developmental issues such as managing emotions and identity development. As such counseling is crucial in helping them better understand issues that affect them and how to deal with such issues. The study found that some cases involving student misconduct are referred for counseling. Most participants mentioned that some students are counseled when they start showing strange behaviors such as overconsumption of alcohol.

Generally, there is an expectation that anyone who goes to college is responsible and with the rules and regulations that are provided, it is expected that students will abide by them. As such, when students breach the rules and regulations it is assumed that those students have problems that require counseling. However, no student who participated in this study mentioned anything related to counseling at the institution. This seems to suggest that students do not know whether these services exist at the institution. Worse still, the study discovered that there is no specific center with skilled professionals for student counseling let alone the dean of students.

Student rules and regulations handbook stipulate that "the dean shall be responsible for student counseling", (p. 9). This was vindicated by some participants who stated that a dean is a focal person in counseling students. However, the position of dean is based on appointment such that the holder of such a position may not have relevant expertise in student affairs such as counseling. A review of the Dean's profile at the institution seems to vindicate this view. Below is a profile of the dean of students who has been anonymized as Dr. Nyasa:

Dr. Nyasa has worked as a student warden for three years before. As an academic, Dr. Nyasa is an Associate Professor of Chemistry in the Department of Chemistry, Faculty of Science, undertaking the teaching of both undergraduate and postgraduate students in Analytical Chemistry and Environmental Chemistry. His main research interests are water and wastewater treatment, development of reliable and robust sample handling, and quantification techniques for profiling of analyses in food, environmental samples, and various other matrices. He has experience working with several instrumentation techniques in analytical chemistry.

This entails that the deans of students who are given this responsibility may not have the necessary skill set in student management which might impede him/her in effectively handling student's issues

\subsection{Impact of student misconduct}

The study also explored the impact of misconduct on student academic life (development). Several impacts were discovered. Firstly, the study discovered that misconduct erodes the credibility of the institution and graduates. Participants indicated that people tend to doubt the moral behavior of the graduate and the credibility of the institution. This hurts the future employment prospects for those graduating. Prospective employers may doubt the moral and intellectual quality of graduates from the institution hence shun away from employing them which consequently may lead to the downfall of the institution. This finding relates to Ogilvie and Stewarts (2010) arguments that misconduct may harm the integrity of the future workforce. This also supports Yakaboski and Birnbaum (2013) assertion that misconduct may result in community distrust, especially for the institution. Consequently, prospective students may not be willing to enroll with the institution to pursue their studies.

Secondly, findings indicate that misconduct compromise the quality of education. This is the case because the study established that the institution mostly employs graduates from the same university. Students that were performing better than their fellow students are identified and recruited as faculty or administrative staff members. This self-sustenance ensures that the costs of recruitment are reduced. This also allows high-quality personnel in terms of intellectual capacity are identified and recruited. However, due to increased cases of misconduct, some of these may not be morally upright which eventually compromises the quality of education. 
Thirdly findings indicate that misconduct causes inconveniences. Participants indicated that misconducts result in unnecessary delays in completing studies. One participant argued that "it is quite difficult to plan that I will finish my studies within a period of four years". The frequency of student's riots and demonstrations results in unnecessary closure of the institutions. This affects the calendar and results in unnecessary delays. Management 3 had this to say:

In Malawi basically, you cannot make a plan that I will go to college, I will do this for four years, from this year to this year. You can't do that because there are a lot of breaks that come as a result of the student's misbehavior, so you can't make a plan. (Personal interview, August 9, 2020)

Other participants in the study also complained that sometimes faculty members are disturbed due to frequent closure of the institution. They mentioned that faculty members keep on repeating the same stuff over and over again and this inconveniences them. This also results in unnecessary wastage of time that would have been invested in something productive. Similarly, other participants stated that misconduct, especially unnecessary demonstrations, affects the calendar of the institution which makes it difficult to plan activities. For example, the study found that due to unnecessary closures the university was running two parallel first-year cohorts which bring a lot of inconveniences to students, faculty members, and management alike.

Fourthly, the study discovered that misconduct wastes public resources. Resources are wasted when students are rioting, demonstrating, or staging a sit-in, or due to frequent closures of the institution. University buses and other properties are also destroyed when students clash with outsiders especially during social or academic trips or when they are staging a demonstration. As such, these institutional properties are supposed to be fixed and maintained. During this period, classes are interrupted and the resources that would have been used are wasted. This finding confirms Langford (2004) argument that misconduct results in lost productivity especially when time is spent handling misconduct rather than being invested in something educational. Management 2 had this to say:

...We had a certain scenario where people broke our bus. Students were coming from the university to the town and they were insulting everybody along the road. So this other day the people said enough is enough they started stoning the bus to the extent that the bus was destroyed (personal interview, August 9, 2020).

Finally, the study discovered that misconduct compromise student holistic development. Students are supposed to become increasingly complex and exemplary as a result of enrolment in the university. Instead, students learn to behave immorally. Consequently, students come out of the university immoral and irresponsible which is a complete opposite of what they are supposed to be.

\section{Conclusions, implications and recommendations}

This study found that institutional culture and poor management style are some of the factors that contribute to student misbehaviors. The study also found that enforcement of rules and regulations, and counseling are some of the ways of addressing student behavior. The study has also found that student misconduct erodes the credibility of the institution and compromises the holistic development of students. This study has several implications for management and students. First, it is imperative for higher education managers to take note that the amount of student learning and development is directly proportional to the amount of involvement in educational programs. More so, since students are in period of identity development, good behavior is that which pleases others hence they copy whatever is acceptable in that society so that they identify with others. In this sense, student involvement in good institutional activities helps them develop a sense of belonging and connection to the institution. Similarly, student participation in campus activities and satisfaction with college experiences increase student persistence and possibly continued good behavior. This, in turn, would reduce the likelihood of engaging in misconduct. The study therefore recommends the inculcation of a sense of ownership 
in students so that they know the importance of their institution and how it will define their future. The study also recommends that there is a need to conduct awareness training and in-service training among staff members so that they know their professional conduct as well as how to manage issues regarding misconduct. The study further recommends Astin (1984) suggestions that management should determine whether the peer group can be consciously used to enhance student involvement in academically oriented programs. In the case of this study, an opportunity exists to use peer influence to increase student participation in institutionally organized activities.

Acknowledgements - Our sincere thanks should go to the public university for allowing us to conduct this study at their institution. Particular thanks should also go to participants who spared their time and made this study a possibility.

\section{References}

Astin, A. W. (1984). Student involvement: A developmental theory for higher education. Journal of College Student Development, 25(4), 297-308.

Barbot, B., \& Hunter, S. R. (2012). Developmental changes in adolescence and risks for delinquency. In E. Grigorenko (Ed.), Handbook of juvenile forensic psychology and psychiatry (pp. 11-34). New Haven, USA: Springer Science + Business Media. https://doi.org/10.1007/978-1-4614-0905-2_2

Başar, H. (2009). Effects of student misbehaviors. In E. Agaoglu (Ed.), Classroom management (pp.131-145). Eskişehir: Anadolu University Press.

Boyer, E. L. (1990). Campus life: In search of community. New Jersey: Library of Congress Cataloging in-Publication Data.

Cohen, L., Manion, L., \& Morrison, K. (2007). Resarch methods in education (6 $^{\text {th }}$ ed.). Milton Park, USA: Routledge.

Creswell, J. W. (2003). Research design: Qualitative, quantitative, and mixed methods approaches (3rd ed.). London: Sage.

Dannells, M. (1997). From discipline to development: Rethinking students conduct in higher education. Washington: George Washington University.

Dunga, S. H. (2012). Financing higher education in Malawi: Prospects challenges and opportunities . In D. Teferra (Ed.), Financing higher education in Africa (pp. 184-213). New York: Palgrave Macmillan. https://doi.org/10.1057/9781137345783_8

Erdem, C., \& Kocyigit, M. (2019). Student misbehaviors confronted by academics and their coping experiences. Education Policy Analysis and Strategic Research. 14(1), 98-115. https://doi.org/10.29329/epasr.2019.186.6

Evans, N. J., Forney, D. S., Guido, F. M., Patton, L. D., \& Renn, K. A. (2010). Student development in college: Theory research and practice (2nd ed). San Francisco: John Wiley \& Sons.

Finn, J. D., Fish, R. M., \& Scott, L. A. (2008). Educational sequelae of high school misbehavior. The Journal of Educational Research, 101(5), 259-274. https://doi.org/10.3200/JOER.101.5.259-274

Forest, J. J., \& Kinser, K. (2002). Student development theory. Higher Education in the United States: An Encyclopedia, pp. 597-603.

Fuchs, M. (2008). Impact of school context on violence at schools: A Muliti-level analysis. International Journal of Violence and Schools, 7(1), 20-42.

Hamrick, F. A., Evans, N. J., \& Schuh J. H. (2002). Foundation of student affairs practice: How Philosophy, theory and Research strengthen educational outcomes. USA: Jossey-Bass.

Hays, P. A. (2004). Case study research. In K. deMarrais \& S. Lapan (eds.), Foundations for research methods of inquiry in education and social sciences (pp. 217-234). New Jersey: Lawrence Erlbaum Associates, Publishers.

Hurst J. C. (1987). Student development and campus ecology. NASPA Journal, 25(1), 5-17.

Iorga, M., Ciuhodaru, T., \& Romedea, S. N. (2013). Ethic and unethic. Students and unethical behavior during 
academic years. Social and Behavioral Sciences, 93, 54-58. https://doi.org/10.1016/j.sbspro.2013.09.151

Kayuni, H. M. (2009). The challenge of studying sexual harassment in higher education: An experience from the University of Malawi Chancellor College. Journal of International Women's studies, 11(2), 83-99.

Korkmaz, I. (2013). Prevention of undesired behaviors. In Z. Kaya (Ed.) Classroom management (pp. 289-311). Ankara: Pegem Akademi.

Kuh, D. G., Kinzie J., Buckley A. J., Bridges K. B., \&, Hayek J.C, (2006). What matters to student success: a review of the literature. Commissioned Report for the National Symposium on Postsecondary Student Success: Spearheading a Dialog on Student Success. National Post-Secondary Education Cooperative.

Kuh, G. D. (2000). Do environments matter? A comparative analysis of the impression of different types of colleges and universities on character. Journal of College and Character, 1(4).

https://doi.org/10.2202/1940-1639.1277

Long, D. (2012). The foundations of student affairs: A guide to the profession. In L. J. Hinchliffe, M. A. Wong, L. J. Hinchliffe, \& M. A. Wong (Eds.), Environments for student growth and development: librerians and student affairs in collaboration (pp. 1-39). Chicago: Association of College \& Research Libraries.

Mayhew, M. J., Caldwell, R. J., \& Goldman, E. G. (2011). Defining campus violence: A phenomenological anaylsis of community stakeholder perspectives. Journal of College Student Development, 52(3), 253-269. https://doi.org/10.1353/csd.2011.0045

Mkandawire, L. (2015). Unima expels eight students for cheating. The Nation on line. http://mwnation.com/154460

Murori, M. (2015). Why is there student unrest in African universities? http://www.edufrica.com/2015/10/

Nkinyangi, J. A. (1991). Students protests in Sub-Saharan Africa. Higher Education, 22, 157-173. https://doi.org/10.1007/BF00137474

Pezza, P. E., \& Bellotti, A. (1995). College campus violence: Origins, impacts and responses. Education Psychology Review, 7(1). https://doi.org/10.1007/BF02214209

Phiri, L., Semu L., \& Madise N. (1994). Violence against women in educational institutions: The case of sexual harassment and rape on chancellor college campus. Research report, Chancellor College

Rodgers, R. F. (1990). Student development. In U. Delworth, G. R. Hanson, \& Associates (Eds.), Student services: A handbook for the profession (2nd ed., pp. 117 - 164). San Francisco: Jossey - Bass.

Rubio, A. (2014). student misconduct and isolation from the school environment: A Study of student, teacher, and administrator perspections of school discipline at an urban middle school. USA: Proquest.

Singini G. (2015). Cash gate style fraud hits Mzuni. The Nation on line. http://mwnation.com/cashgate-style-fraud-hits-mzuni/

South African council of Educators. (2011), School based violence report: An overview of school-based violence in South Africa. SACE: South Africa.

Teferra, D., \& Altbach, P. (2004). African higher education: Challenges for the 21st century. Higher Education, 47, 21-50. https://doi.org/10.1023/B:HIGH.0000009822.49980.30

Tinto, V. (1993). Leaving college: Rethinking the causes and cures of student attrition. (2nd ed.).Chicago: University of Chicago Press. https://doi.org/10.7208/chicago/9780226922461.001.0001

Wearmouth J., Glynn T, \& Berryman, M. (2005) Perspectives on student behavior in schools: Exploring theory and developing practice. London: Routledge.

World Bank. (2014). The education system in Malawi. Retrieved from http://wwwwds.worldbank.org/external/default/

Wynne, S. L., \& Joo, H .J. (2011). Predictors of school victimization: Individual, familial and school factors . Crime and Delinquency, 57(3), 458-488. https://doi.org/10.1177/0011128710389586

Yin, R. K. (2009). Case study research, design and methods (Vol. 5, $4^{\text {th }}$ ed). London: Sage. 